\title{
A EDUCAÇÃO RURAL BRASILEIRA ANALISADA POR LOURENÇO FILHO NO INÍCIO DA DÉCADA DE $1960^{1}$
}

\author{
Macioniro Celeste Filho ${ }^{2}$
}

\section{RESUMO}

Lourenço Filho foi um dos mais importantes intelectuais a influenciar os rumos da educação brasileira no século XX. Nas décadas de 1950 e 1960, atuando em organismos internacionais como a Organização dos Estados Americanos (OEA), ele analisou a trajetória da educação rural nas Américas. Em 1962, Lourenço Filho escreveu um estudo para a OEA sobre a educação rural, que não foi publicado no Brasil. É propósito do atual trabalho apresentar o que este intelectual abordou da educação rural brasileira neste texto enviado à OEA. A metodologia utilizada foi a de análise documental sobre o texto de Lourenço Filho. Tem-se por objetivo apresentar a contribuição inédita em publicações brasileiras deste autor ao tratar a educação rural no início da década de 1960.

Palavras-chave: Educação rural, Lourenço Filho, Organização dos Estados Americanos.

\footnotetext{
${ }^{1}$ Este artigo é resultado parcial de pesquisas para o projeto Formação e Trabalho de Professoras e Professores Rurais no Brasil: PR, SP, MG, MT, PE, PI, SE, PB, RO (décadas de 40 a 70 do século XX), coordenado pela Prof ${ }^{a}$. Dr ${ }^{a}$. Rosa Fátima de Souza, da UNESP de Araraquara/SP e financiado pelo CNPq.

2 Universidade Estadual Paulista (UNESP), Bauru/SP, Brasil.
} 


\title{
LA EDUCACIÓN RURAL BRASILEÑA ANALIZADA POR LOURENÇO FILHO A PRICIPIOS DE LA DÉCADA DE 1960
}

\section{RESUMEN}

Lourenço Filho ha sido uno de los más importantes intelectuales a influenciar los rumbos de la educación brasileña en el siglo XX. En las décadas de 1950 y 1960, actuando en organismos internacionales como la Organización de los Estados Americanos (OEA), analizó la trayectoria de la educación rural en las Américas. En 1962, él escribió un estudio para la OEA sobre la educación rural, que no fue publicado en Brasil. Es propósito del actual trabajo presentar lo que este intelectual abordó de la educación rural brasileña en este texto enviado a la OEA. La metodología utilizada ha sido la de análisis documental sobre el texto de Lourenço Filho. Se tiene por objetivo presentar la contribución inédita en publicaciones brasileñas de este autor al tratar la educación rural a principios de la década de 1960.

Palabras clave: Educación rural, Lourenço Filho, Organización de los Estados Americanos.

\section{THE BRASILIAN RURAL EDUCATION ANALYZED BY LOURENÇO FILHO IN THE EARLY 1960S}

\begin{abstract}
Lourenço Filho was one of the most important intellectuals to influence the direction of Brazilian education in the 20th century. In the 1950s and 1960s, working in international organizations such as the Organization of American States (OAS), he analyzed the trajectory of rural education in the Americas. In 1962, Lourenço Filho wrote a study for the OAS on rural education, which was not published in Brazil. It is the purpose of the present work to present what this intellectual approached Brazilian rural education in this text sent to the OAS. The methodology used was the documentary analysis on the text of Lourenço Filho. The objective is to present the unpublished contribution in Brazilian publications of this author when dealing with rural education in the early 1960 .
\end{abstract}

Keywords: Rural education, Lourenço Filho, Organization of American States.

\section{L'Éducation rurale brésilienne analysée par lourenço filho au début des années 1960}

\section{RÉSUMÉ}

Lourenço Filho fut l'un des intellectuels les plus importants à influencer le cours de l'enseignement brésilien au XXème siècle. Dans les années 1950 et 1960, en agissant au sein d'organismes internationaux comme l'Organisation des Etats Américains (OEA), il analysa la trajectoire de l'enseignement rural aux Amériques. En 1962, il mena une étude pour l'OEA à propos de l'enseignement rural, qui ne fut pas publiée au Brésil. Le travail ci-après a pour but de présenter ce que cet intellectuel évoqua concernant l'enseignement rural brésilien dans ce texte envoyé à l'OEA. La méthodologie employée a été celle de l'analyse documentaire du texte de Lourenço Filho. L'objectif est de présenter la contribution inédite de cet auteur aux publications 
Revista História da Educação (Online), 2019, v. 23: e89570

brésiliennes, en traitant le sujet de l'enseignement rural au début des années 1960.

Mots-clés: Éducation rurale, Lourenço Filho, Organisation des États Américains. 


\section{INTRODUÇÃO}

Nas mais distintas áreas de produção cultural e nos mais diversos órgãos governamentais, Manoel Bergström Lourenço Filho foi um dos mais influentes intelectuais a determinar os rumos institucionais da educação brasileira no século XX. Nas décadas de 1950 e 1960, atuando em organismos internacionais de cultura, Lourenço Filho dedicou esforços à compreensão e à elaboração de políticas públicas que equacionassem os desafios da educação rural na América Latina. É propósito do atual trabalho apresentar o estudo inédito de Lourenço Filho sobre educação rural datado de dezembro 1962 e enviado no início do ano seguinte, como sua contribuição aos debates sobre este tema, ao Comitê de Ação Cultural, órgão da Organização dos Estados Americanos - OEA. Trata-se de seu estudo intitulado Educação rural: documento preparado para a IV Reunião do Conselho Interamericano Cultural - Organização dos Estados Americanos.

Segundo o minucioso estudo bibliográfico organizado por Carlos Monarcha e Ruy Lourenço Filho (2001), o texto Educação rural, de Lourenço Filho (1962) não foi publicado no Brasil. Pretende-se no atual trabalho sintetizar o que Lourenço Filho apresentou sobre a educação rural brasileira à OEA no início da década de 1960. Como ele descrevia situações bem-sucedidas desta atividade educacional? Quais exemplos de ações de educação rural ocorriam no Brasil? Quais as suas práticas e seus limites de atuação no mundo rural brasileiro? Com este intuito, a metodologia utilizada foi a análise documental das fontes disponíveis sobre este trabalho de Lourenço Filho. Os documentos obtidos para este estudo são o texto original de 108 páginas, datilografado e com muitas anotações manuscritas nele pelo próprio Lourenço Filho (1962); os exemplares do Boletin de actas das reuniões do Comitê de Ação Cultural da OEA, de sua $337^{\mathrm{a}}$ Reunião Ordinária, de 15/01/1963, à 376 a Reunião Ordinária, de 15/o8/1963, que debateram a elaboração de um documento da OEA sobre educação rural a partir do estudo enviado por Lourenço Filho, privilegiadamente as atas OEA (1963a), OEA (1963b) e OEA (1963c); e o 
resultado final desta contribuição internacional com a elaboração do documento oficial de 148 páginas da OEA (1963d), intitulado Estudio sobre educación rural. 3 O texto pioneiro de Rosa Fátima de Souza (2013), abordando a concepção de Lourenço Filho sobre a educação rural a partir de sua experiência no México na década de 1950, será referência importante no atual trabalho. Tem-se por objetivo apresentar a contribuição inédita em publicações brasileiras de Lourenço Filho ao analisar a educação rural no início da década de 1960. Este intelectual dominava profundamente os temas por ele tratados, portanto, sua percepção dos processos educacionais brasileiros ainda demonstra pertinência e pode ser relevante atualmente nos debates sobre educação rural em nosso país.

Carlos Monarcha e Ruy Lourenço Filho ressaltaram uma das principais características de Manoel Bergström Lourenço Filho. A sua atuação foi paradigmática como marco divisório entre a intelectualidade dedicada privilegiadamente à vida acadêmica e um pensador engajado nas questões políticas, institucionais e profissionais num novo contexto, o das rápidas transformações sociais brasileiras do início a meados do século XX:

\begin{abstract}
Analisada, agora, com distanciamento e em perspectiva histórica, pode-se dizer que a produção intelectual de Lourenço Filho afasta-se deliberadamente da tradição ensaística, que caracteriza o pensamento social de seu tempo, adotando um estilo de reflexão de padrão científico-acadêmico, impulsionado tanto pela inovação teórica, quanto pelas urgências sociais, políticas e administrativas. Noutras palavras, sua produção intelectual está inserta, de um lado, no movimento ascendente de especialização, legitimação e institucionalização das ciências humanas e sociais, fundação das universidades, expansão do mercado editorial, modernização/racionalização do aparelho de Estado; e, de outro, na experiência urbanizadora, irrupção dramática de ideologias e advento das massas populares na cena política. Mas, sobretudo, esse esforço criador está inserto em um tempo histórico no qual o tema da educação nacional ocupava uma centralidade - hoje perdida - tanto
\end{abstract}

3 Agradeço a Stella Villagran, da Columbus Memorial Library, e a Rene Gutierrez, dos arquivos da OEA, ambos em Washington, D. C., pela inestimável ajuda na localização desta documentação. 
no discurso oficial quanto no pensamento social brasileiros, o que possibilitou a ascensão em âmbito nacional dos chamados "educadores profissionais", responsáveis pela produção, legitimação e institucionalização da reflexão sobre educação concebida como conhecimento irredutível. (MONARCA; LOURENÇO FILHO, 2001, p. 12)

Como um dos principais educadores profissionais do país, ele atuou num tempo em que a educação nacional era central na reflexão social brasileira. Seu texto de 1962 sobre a educação rural talvez seja um dos últimos de Lourenço Filho a encerrar as possibilidades de análise engajada de um intelectual no campo educacional como se fazia até então. Em meados da década de 1960, sob novo ciclo autoritário, gradativamente, a educação deixa de ser o vórtice do pensamento social brasileiro e a produção intelectual de Lourenço Filho, não por acaso, também declina. A análise de seu estudo dedicado à educação rural fornece a possibilidade de averiguarmos o ápice e, paradoxalmente, a despedida de um tipo de atuação intelectual representada exemplarmente pela trajetória de Lourenço Filho.

\section{LOURENÇO FILHO E A EDUCAÇÃO RURAL NO MÉXICO NA DÉCADA DE 1950}

O Conselho Interamericano Cultural, para o qual Lourenço Filho enviou seu estudo sobre a educação rural no início de 1963, tinha sede no México. Quais as relações de Lourenço Filho com este país? Rosa Fátima de Souza (2013, p. 62-63) sintetizou os estudos dele no México:

Em 1951, o educador brasileiro Manoel Bergström Lourenço Filho realizou uma viagem de estudos ao México a pedido do Ministro da Educação e Saúde, Simões Filho, com o objetivo de conhecer e avaliar o movimento de educação rural em desenvolvimento naquele país. Como resultado da visita, Lourenço Filho apresentou um relatório circunstanciado intitulado A educação rural no México (LOURENÇO FILHO, 1951). Esse relatório foi divulgado no Brasil 
para os órgãos da administração do ensino dos vários estados da federação brasileira, foi publicado em periódico educacional de circulação nacional (LOURENÇO FILHO, 1952) e, em 1961, compôs um dos capítulos do livro Educação comparada, de autoria do educador (LOURENÇO FILHO, 1961). [...] O relatório intitulado A educação rural no México, elaborado por Lourenço Filho no final de 1951, constitui-se em um detalhado documento sobre princípios, concepções, estrutura e organização da educação rural mexicana.

Para entender a trajetória de Lourenço Filho até sua atuação no México, Rosa Fátima de Souza (2013, p. 65-66) resumiu alguns dos cargos institucionais ocupados por ele:

Em 1937, [Lourenço Filho] foi nomeado membro do Conselho Nacional de Educação e passou a exercer o cargo de Diretor-Geral do Departamento Nacional de Educação, do Ministério da Educação e Saúde. Nesse período trabalhou na implantação do Instituto Nacional de Estudos Pedagógicos (INEP), órgão vinculado ao Ministério da Educação, o qual dirigiu até 1946. Ao deixar a direção do INEP, ocupou, pela segunda vez, o cargo de Diretor-Geral do Departamento Nacional de Educação. [...] Lourenço Filho já havia visitado o México anteriormente e participado em 1947 da III Conferência Geral da UNESCO. O retorno em 1951 tinha uma finalidade política bem definida. Tratava-se de examinar com profundidade as práticas de educação rural levadas a termo no México, aprender bem as lições para implementar políticas semelhantes no Brasil. Ainda no ano de 1951, Lourenço Filho deixou a direção do Departamento Nacional de Educação, sendo nomeado Presidente da Comissão Executiva do Centro de Formação para Educação Fundamental na América Latina e representou o Brasil no Conselho Interamericano Cultural, ambos com sede no México.

Constata-se, portanto, que Lourenço Filho tinha bom trânsito nos organismos vinculados à OEA com sede no México, pois na década de 1950 fora o representante brasileiro em seu Conselho Interamericano Cultural. Percebemse daí os motivos que levaram Lourenço Filho a propor a este Conselho, em 1963, a discussão e elaboração de uma síntese dos seus estudos sobre educação rural nas Américas. Isto ocorreu provavelmente com o propósito de divulgar aos demais países americanos sua análise sobre o papel da educação rural neste 
continente. Ele pretendia possivelmente que algum documento oficial da OEA, resultante desta sua iniciativa, influísse na formulação das políticas públicas sobre educação rural no Brasil no conturbado período das propostas de reformas de base do governo João Goulart. A formulação de tal documento acabou ocorrendo com a oficialização das conclusões do estudo de 1962 de Lourenço Filho, tomadas como recomendação aos países membros da OEA através da Resolução $\mathrm{V}$ da Terceira Reunião do Conselho Interamericano Cultural, de agosto de 1963, anexa ao término do atual trabalho.

Rosa Fátima de Souza destaca uma importante característica no processo de estudo comparativo utilizado por Lourenço Filho em seu texto de 1951 sobre o México. Trata-se de uma espécie de instrumentalização do que se comparara com finalidades privilegiadamente pedagógicas, deixando em segundo plano as características políticas originais que resultaram nos arranjos educacionais a serem comparados:

Com o relatório A educação rural no México, Lourenço Filho ofereceu ao governo e aos educadores brasileiros uma referência exemplar sobre educação rural. Da experiência mexicana profundamente marcada pelos processos de revolução social, o autor extraiu mais os elementos técnico-pedagógicos que convinham à realidade brasileira. Nesse sentido, no texto de Lourenço Filho, a força política da luta dos camponeses pela terra, motivação norteadora da pedagogia mexicana, foi minimizada. [...] Dessa maneira, a referência aos princípios revolucionários que mobilizaram e alimentaram a pedagogia social presente nas práticas de educação rural mexicanas foi vista apenas como um componente da trajetória histórica do movimento, pois interessava mais ao autor assinalar a reconfiguração do movimento no contexto democrático. (SOUZA, 2013, p. 76-77)

Esta característica será mantida no estudo comparativo de Lourenço Filho sobre educação rural nas Américas enviado à apreciação da OEA em 1963.

Em sua pesquisa do início da década de 1960, Lourenço Filho ampliou o escopo dos países comparados. Desta vez, foram 20 países americanos, inclusive com dados sobre os Estados Unidos. No entanto, o foco privilegiado continuou 
sendo o México; secundariamente, o Brasil. Os demais países aparecem em tabelas comparativas e em algumas situações de ações educacionais bemsucedidas, como é o caso, por exemplo, dos núcleos escolares campesinos da Bolívia e do Peru. De onde Lourenço Filho tirou informações para um estudo comparativo de tal envergadura? Para o caso mexicano, atualizando dados estatísticos, o autor retomou sua análise do início da década anterior. Para os demais países, além da bibliografia referendada por ele, que será aqui apresentada posteriormente de maneira circunstancial, Lourenço Filho (1962, p. 1-2) indicou que:

\footnotetext{
Será preciso observar que a descrição de certos aspectos especiais [da educação na América], entre os quais precisamente figuram os da educação rural, ressente-se de muitas lacunas. Para o efeito deste estudo muitas delas puderam ser sanadas mediante consulta ao levantamento que, sobre a vida rural, está fazendo o Centro LatinoAmericano de Pesquisas em Ciências Sociais, das Nações Unidas, com sede no Rio de Janeiro. Mas esse valioso trabalho ainda não se acha concluído.
}

Lourenço Filho afirmou explicitamente, na página de abertura de seu texto, que mesmo não tendo sido concluído, ele teve acesso a resultados parciais do estudo impulsionado pela UNESCO, no Rio de Janeiro, do Centro LatinoAmericano de Pesquisas em Ciências Sociais - CLAPCS - sobre a situação rural na América Latina. O estudo a que Lourenço Filho tivera acesso em 1962 foi aprofundado e publicado em 1965 pelo CLAPCS com o título de Situação social da América Latina.

Para os interessados na educação rural mexicana, seria mais apropriada a leitura do texto de Lourenço Filho de 1951 e sua comparação com o de 1962. Não foi o que se pretendeu fazer aqui. No espaço de um artigo, é inviável acompanhar a comparação de vinte países feita por Lourenço Filho; seria quase que reproduzir na íntegra o texto original dele de 1962. Portanto, no atual trabalho decidiu-se privilegiar o que Lourenço Filho abordou da educação rural brasileira. Este seria o foco. Contudo, não se pode desconsiderar que a estrutura 
do trabalho de 1962 de Lourenço Filho era comparativa. Assim, às vezes, a experiência sobre a educação rural brasileira também emerge deste processo de comparação. Isto é, o que os outros países faziam e nós não? Neste sentido, a educação rural brasileira também foi apresentada por Lourenço Filho pelas suas lacunas. Ele apontou percursos onde outras nações conseguiram avançar em processos de educação rural nos quais ainda engatinhávamos.

\section{AS FONTES DOCUMENTAIS}

Antes de prosseguir, torna-se necessário diferenciar as duas versões encontradas do estudo de Lourenço Filho. A primeira, dele, de dezembro de 1962; e a que resultou após a apreciação executada pela OEA no primeiro semestre de 1963. No acervo documental de Lourenço Filho, preservado no CPDOC-FGV, no Rio de Janeiro, encontra-se arquivado o original datilografado do texto de Lourenço Filho sobre educação rural datado de dezembro de 1962. Este original contém inúmeras alterações manuscritas pelo próprio autor, como pode ser exemplificado na figura 1:

Figura 1: Manuscrito Lourenço Filho

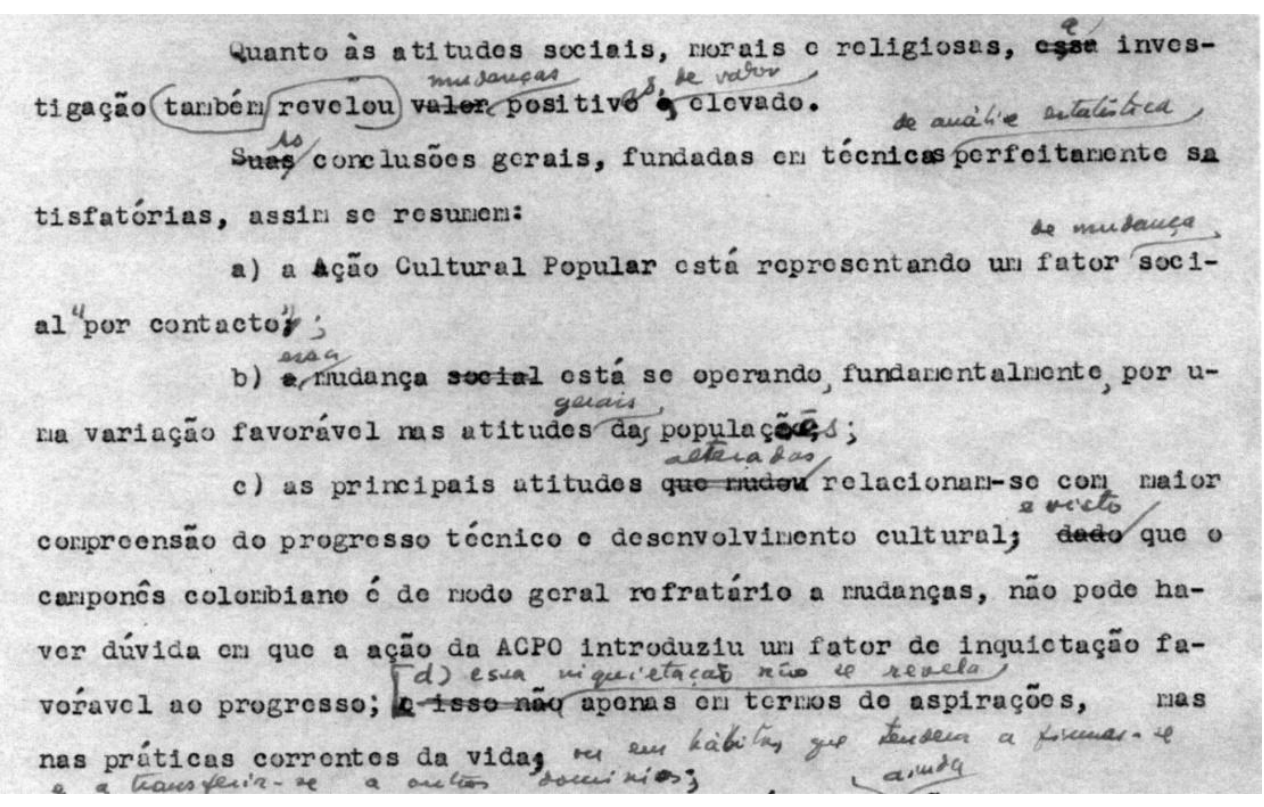


Fonte: Lourenço Filho (1962, p. 64)

Após a revisão manuscrita, certamente outra versão do texto foi datilografada. Esta nova versão datilografada deve ter sido então enviada à OEA no início de 1963. Buscou-se com determinação, mas infelizmente não foi possível localizar na Columbus Memorial Library e nem nos arquivos da OEA, ambos em Washington, D. C., o exemplar do texto de Lourenço Filho recebido pela OEA em 1963. Ao término do processo de avaliação deste texto, a OEA produziu versão adaptada dele, em espanhol, datada de agosto de 1963. Ambas são muito próximas. O que as diferencia são mudanças na redação de alguns trechos e ajustes de dados estatísticos, informados pelos diversos membros do Comitê de Ação Cultural da OEA. Para o atual trabalho, foram utilizadas as duas versões do texto. Contudo, para efeito de fidelidade à obra, as referências serão do texto original de Lourenço Filho de 1962.

A metodologia de análise documental aqui executada foi a de cotejar as duas versões encontradas do texto redigido por Lourenço Filho sobre a educação rural nas Américas no início da década de 1960: a que se encontra em seu acervo no arquivo do CPDOC-FGV, no Rio de Janeiro, e a versão adaptada que se encontra nos arquivos da OEA na Columbus Memorial Library, em Washington, D.C., nos EUA. Buscou-se averiguar se as divergências eram significativas. Quando discordantes, para efeito de análise, optou-se sempre pelo original arquivado no Rio de Janeiro. Contudo, pode-se antecipar que as diferenças entre ambas as versões são, na maioria, de atualização de dados estatísticos informados pelo autor. Acompanhou-se a composição da versão adaptada através da leitura das atas das reuniões em 1963 do Comitê de Ação Cultural da OEA em que foram feitas tais alterações. Contudo, numa dessas reuniões, uma tentativa de mudança gerou polêmica neste comitê. Esse caso específico será abordado na parte final do atual trabalho. Não foram criadas categorias de análise novas que se sobrepusessem ou desrespeitassem a estrutura original do texto de Lourenço Filho. Foi executada no atual estudo uma descrição sintética do que o próprio autor ordenou em seu trabalho, do 
jeito em que ele o organizou, na sequência por ele elaborada. Dessa maneira, o presente texto pretende dar significado elucidativo ao que o próprio Lourenço Filho elaborou nos primórdios dos anos 1960 sobre a educação rural.

Ao tratar da formação intelectual de Lourenço Filho, Mirian Warde (2003, p. 145) destacou como ele agia como membro de uma ampla rede de pensadores:

Inscrição geracional, pertença a redes intelectuais ou políticas, laços de sociabilidade; para cada um desses marcos, há que se prestar atenção na reconstituição do que se pode chamar de trajetória ou itinerário de formação de um intelectual. Em se tratando de um intelectual, ainda que não estritamente acadêmico, como Lourenço Filho, não há como dispensar em meio a esses marcos o papel específico que professores possam ter exercido como balizadores do trajeto.

A autora analisou as redes intelectuais e os laços de sociabilidade na trajetória de Lourenço Filho nas primeiras décadas do século XX. No atual caso, pode-se perceber a ampliação deste itinerário intelectual de atuação internacional mantidos por ele na OEA. No entanto, há algo recorrente em tal trajetória: o papel marcante que a experiência de outros professores exerceu em sua atuação coletiva.

Na década de 1950, como representante brasileiro no Conselho Interamericano Cultural, Lourenço Filho criou laços de sociabilidade com outros intelectuais deste órgão assessor da OEA, entre eles, com Francisco S. Céspedes, educador com vasta carreira como professor em diversas instituições de ensino do Panamá. Como Diretor Adjunto do Departamento de Assuntos Culturais da OEA, foi Francisco S. Céspedes quem apresentou o estudo de Lourenço Filho ao Comitê de Ação Cultural da OEA em sua reunião de 15 de janeiro de 1963 (OEA, 1963a, p. 5-6). Ele propôs que tal texto fosse usado como base de um estudo da OEA sobre a educação rural nas Américas. É solicitada à sede da OEA, em Washington, D. C., a tradução do texto para o espanhol (OEA, 
1963a, p. 6). As cópias mimeografadas da versão em espanhol foram entregues aos membros do Comitê de Ação Cultural em sua reunião de 7 de março de 1963 (OEA, 1963b, p. 32-33). A partir de então, na maioria das reuniões subsequentes, foram analisadas e aprovadas algumas alterações de partes sequenciais do estudo do Lourenço Filho. Esta sistemática ocorreu de março a agosto de 1963. Com uma única exceção, que será tratada posteriormente, este processo não despertou controvérsias ou embates no Comitê de Ação Cultural da OEA. Ele se deu por consenso. O resultado tornou-se, em agosto de 1963, a resolução oficial da OEA (1963d) sobre a educação rural nas Américas a ser recomendada aos seus países membros.

\section{LOURENÇO FILHO E A EDUCAÇÃO RURAL NO INÍCIO DA DÉCADA DE 1960}

É importante ressaltar a coerência do itinerário intelectual de Lourenço Filho. Ele não tinha uma percepção dos processos educacionais apenas através de postulados teóricos. Mirian Warde (2003, p. 142) destacou seu pragmatismo:

Quer na formação como normalista, quer na docência primária e normal, desde a segunda parte dos anos de 1910, Lourenço Filho constituíra o seu arsenal intelectual em ambientes escolares tangidos pelos vetores mais diversos. Na sua formação, instrumentou-se para pensar e conduzir suas práticas na direção da renovação; mas as escolas nas quais Lourenço Filho trabalhou eram amálgamas de práticas antigas e novas; de intervenções renovadoras e de resistências. O seu arsenal pedagógico, portanto, não fora constituído desde fora da escola, nem de idílicas condições. A perspectiva que sedimentou sobre o que e como fazer para formar professores habilitados para as listas do ensino foi composta de uma parte nodal de suas experiências docentes diretas; uma outra parte foi fornecida pelos experimentos psicopedagógicos que controlou, dos quais extraiu uma série de diagnósticos de processos de ensino-aprendizagem tanto em ambientes de práticas consagradas como em ambientes de práticas renovadas. 
A experiência educacional efetiva perpassa integralmente seu estudo sobre a educação rural nas Américas. Nesse sentido, a análise executada por Lourenço Filho renova seu arsenal pedagógico ao tentar entender como outras experiências educacionais em regiões rurais americanas transitaram entre os ideais e as práticas efetivas. Com esse intuito, Lourenço Filho (1962, p. 1) dividira seu estudo sobre a educação rural em três partes:

A primeira, de caráter introdutório, apresenta as disposições legais sobre a matéria, e alguns índices pelos quais desde logo se encaminha uma visão funcional da educação rural. A segunda, mais extensa, relata as experiências, agrupadas por seus objetivos imediatos, condições de operação e resultados. Finalmente, a terceira formula proposições gerais na forma de denominadores comuns, a eles juntando algumas observações resultantes da análise tabular de indicadores demográficos, econômicos e sociais.

Na introdução de seu texto, Lourenço Filho (1962, p. 3) conceituou o que entendia por educação rural:

A expressão educação rural participa, em princípio, do mesmo sentido abrangente, incluindo atividades escolares e extra-escolares, de uma e outra espécie. O que o adjetivo rural faz é delimitar-lhes o campo de aplicação a certas áreas, especialmente caracterizadas por dispersão demográfica e tipos de ocupação predominantes, além de o serem por critérios subsidiários que no devido tempo examinaremos, visto que apresentam diferenciação de um país para outro. A conceituação básica parte da caracterização de um certo espaço, o rural, contraposto a outro, o urbano. Ainda que para aquele se admitam todas as formas educativas, escolares e extra-escolares, a verdade é que no conjunto dos textos legais a expressão se refere à educação escolar, ou ensino, $\mathrm{e}$ mais precisamente a ensino de grau primário, por isso que nas zonas rurais é ele o de maior extensão, senão o único a ter existência.

Mesmo tendo ressaltado previamente que há grande diferenciação de características das áreas rurais de um país a outro, o autor definiu economicamente as zonas rurais das Américas: 
A percepção geral das necessidades do ambiente rural relaciona-se, no entanto, com o predomínio das atividades econômicas da população. Geralmente, são as de produzir bens que atendam as primeiras necessidades, ou, tecnicamente, atividades do setor econômico primário: caça, pesca, atividades extrativas, criação de gado e agricultura. Todas exigem extensões de terra relativamente grandes, o que em geral determina mais baixa densidade da população. (LOURENÇO FILHO, 1962, p. 6)

Depois desta conceituação inicial, Lourenço Filho (1962, p. 7) derivou as consequências educacionais destas características:

Aos critérios de mais fácil discriminação objetiva, como os de dispersão demográfica e produção, outros assim se podem somar-se. Há o caso de núcleos urbanos, assim administrativa e estatisticamente considerados, que funcionalmente são rurais; e, ao contrário, os que embora chamados rurais, são funcionalmente urbanos. Esse fato particularmente se observa no Brasil, com zonas muito diversamente desenvolvidas, mas com um só tipo de classificação políticoadministrativa. Nesse país, há sedes municipais, sempre chamadas cidades, com pouco mais de uma centena de habitantes e vida tipicamente rural, embora as escolas nela existentes se classifiquem como urbanas. O que praticamente se verifica, na generalidade dos casos, é o seguinte:

a) aplicado ao nome educação o adjetivo rural designa ensino primário ou elementar;

b) é ele mais comumente ministrado em escolas de organização rudimentar, com uma só classe e um só professor, em razão da dispersão demográfica, ou mesmo da falta de edifícios escolares em que possam funcionar escolas graduadas;

c) as relações entre tais escolas e os órgãos administrativos de assistência técnica, supervisão e controle, são geralmente tênues ou pouco eficientes;

d) os mestres, em geral, têm formação pedagógica inferior, ou mesmo nenhuma formação desse tipo.

Nesta primeira, de três partes do seu texto, após as considerações conceituais iniciais, o autor usou dados estatísticos e de informações pontuais sobre diversos países americanos. A estrutura seguida foi de descrever a extensão dos estudos primários de cerca de vinte países; seus planos de estudos 
e programas das escolas rurais; a preparação dos professores, incluindo os professores sem formação pedagógica; o financiamento à educação; a obrigatoriedade e oferta de ensino; os tipos de escolas rurais; e dados sobre a evasão escolar.

Na segunda parte de seu estudo, Lourenço Filho analisou experiências bem-sucedidas de educação rural. Ele destacou a necessidade de inserção de tais experiências no contexto sócio-histórico em que ocorriam:

As escolas não funcionam no vazio. Têm o seu ambiente próprio em relação ao qual se há de definir um trabalho de sentido funcional, derivado das expectativas sociais das famílias, o que vale dizer dos fatores que para tais expectativas concorram os modos de vida de cada grupo e suas relações com a vida regional e nacional. (LOURENÇO FILHO, 1962, p. 41)

Caso tal inserção social não se efetivasse, o resultado seria a evasão escolar:

Os casos sobre evasão escolar revelam é que populações rurais nem sempre aceitam o trabalho escolar que se oferece. Carregando-se nas tintas, pode-se dizer o seguinte: a cidade deseja educar as populações rurais e assim as leis preceituam; mas essas populações não querem ser educadas ou, ao menos, não o desejam nos moldes do existente. (LOURENÇO FILHO, 1962, p. 36)

$\mathrm{O}$ autor dividiu as experiências bem-sucedidas de educação rural em três grupos. O primeiro era o das experiências que tivessem buscado a maior extensão dos serviços educativos ou a melhoria de sua qualidade. No segundo grupo constavam as experiências tendentes a valorizar a escola num trabalho de extensão cultural. O terceiro grupo era o de experiências que procuraram influir na organização das comunidades rurais, que visaram integrar os serviços de educação rural com outros serviços do Estado (LOURENÇO FILHO, 1962, p. 4142). 
Após esta divisão, o autor avaliou exemplos de tais experiências de educação rural. Como mencionado anteriormente, no atual trabalho serão ressaltadas as experiências brasileiras. No primeiro grupo, o Brasil era exemplo na construção de escolas rurais:

Brasil - Um intenso programa de construções de escolas rurais foi nesse país iniciado em 1946, quando se regularizou a aplicação de recursos do Fundo Nacional do Ensino Primário, criado alguns anos antes, mas que só então teve a sua legislação completada. Caracterizase como programa cooperativo de grande extensão, entre o governo federal de uma parte e o de cada Estado e órgãos da administração municipal, de outra. O governo federal fornece os recursos e os projetos de construção, opina sobre a proposta de localização das escolas e fiscaliza os trabalhos. Os municípios e, em certos casos, os Estados doam os terrenos para as construções, ou os obtêm de particulares. Em qualquer hipótese, os Estados respondem pela execução de cada projeto, comprometendo-se a criar e manter escolas onde elas não existam, precisamente por falta de locais adequados.

O montante dos auxílios distribuídos anualmente a cada Estado fica na dependência do vulto dos recursos gerais do Fundo, dos quais 70\% devem ser empregados em construções. Os critérios para a distribuição dessa parcela são objetivos, envolvendo a análise dos dados referentes à população sem escolas, aos esforços de cada Estado no cumprimento das obrigações constitucionais com a educação em geral, e a taxa de analfabetismo de cada região. Os dados publicados sobre a execução do programa, no decênio 1946-1955, mostram que nesse prazo foram construídas 6.579 escolas rurais primárias, com área variável entre 80 e $225 \mathrm{~m}^{2}$, cada uma. No fim desse último ano, estavam em fase de acabamento mais 367 unidades, o que perfazia o total de 6.804 escolas, a maior parte com residência para o professor. $\mathrm{O}$ número total de salas de aula era de 7.206, correspondentes a um aumento de matrícula de 288 mil alunos. Para isso, empregaram-se 474 milhões de cruzeiros na construção propriamente dita e mais 83 milhões em mobiliário e equipamento. Nos anos subsequentes, o plano foi modificado para a inclusão de construção de escolas urbanas. Já em 1956, fizeram-se construir 367 salas. Perdeu assim o caráter essencialmente rural de origem. Não obstante, naquela primeira fase, enriqueceu em muito as instalações destinadas ao ensino rural em todas as regiões do país e sobretudo nas mais carentes delas.

Os resultados práticos podem ser assim resumidos: a) as construções permitiram criar numerosas escolas rurais em povoações onde isso antes se tornava impossível; b) permitiram consequentemente a elevação da matrícula rural; c) ajudaram a radicar o professor na zona rural pelo simples fato de ele poder contar com residência satisfatória; 
d) no caso de povoações de certas zonas de população mais disseminada, dada a criação de novas escolas, tiveram os governos estaduais de estabelecer escolas normais rurais para atender a essas áreas antes desprovidas de centros de formação de professores; e) de modo geral, as residências dos professores passaram a servir como modelo para construções residenciais em muitas comunidades. Quanto a esse último ponto, é de notar que não se tratava de residências luxuosas, mas dotadas de boas instalações sanitárias, espaço para jardim, horta e criação de pequenos animais. Os projetos permitiram adaptação a condições de clima de cada região e o emprego de material disponível em cada uma. Durante a execução do programa, o aumento de matrícula nas áreas rurais foi paralelo ao número de novas escolas construídas, não deixando dúvida, portanto, no acerto da providência quanto ao aspecto da extensão dos serviços escolares nessas áreas. (LOURENÇO FILHO, 1962, p. 44-46)

Para esta caracterização da expansão de escolas rurais brasileiras nas décadas anteriores, Lourenço Filho (1962, p. 46) citou em nota de rodapé como fonte dos dados utilizados os estudos de Robert King Hall (1950) e do INEP (1957).

No que se refere à formação especializada do magistério rural, mesmo dos professores sem formação pedagógica, Lourenço Filho novamente destaca a necessidade de contextualização social para compreender o desempenho destes docentes; isto é, sem condições materiais concretas de fixação do docente no meio rural, não será a formação dele que o fará:

É evidente que não basta que se adotem novos planos, teoricamente excelentes, mas que mesmo assim não funcionem na prática. $\mathrm{E}$ ainda mais: será necessário verificar até que ponto essa formação vem a concorrer para a estabilidade dos mestres rurais, ou de sua permanência nas escolas para as quais se tenham preparado. Para essa estabilidade, o tipo de formação não basta. Há outras condições a considerar, como satisfatória remuneração, assistência técnica e social, e outros estímulos de integração profissional. Em grande número de casos, mesmo com formação especializada que se presuma a melhor, os professores abandonam as escolas rurais para servirem em escolas urbanas, ou deixam mesmo a profissão, como têm demonstrado diferentes pesquisas. Essas são as razões de ordem geral que têm levado numerosos países a admitirem no ensino rural uma percentagem muito elevada de professores não-titulados, como antes 
se viu. (LOURENÇO FILHO, 1962, p. 50)

Como base desta análise, Lourenço Filho (1953) citou seu trabalho para a UNESCO em co-autoria com L. A. Creedy, E. A. Pire e Isidro Castillo.

Segundo o autor, havia duas graves lacunas nas ações brasileiras quanto à educação rural: inexistência de programas de material de ensino em línguas autóctones, isto é, material didático em línguas indígenas; e, especialmente, a ausência de articulação das escolas de um só mestre com escolas centrais, compondo possíveis núcleos escolares campesinos:

Esse movimento visa, de uma parte melhorar a oferta do ensino quanto à extensão dos cursos que se oferecem às populações rurais. Mas, de outra, tem procurado melhorar as condições da administração escolar de modo a facilitar também certos trabalhos de extensão social que as escolas devam realizar. Nesse caso, os ensaios se desenvolvem em outra modalidade, geralmente chamada de núcleos escolares, e também de escolas centrais, porque obedecem a este esquema geral: uma escola, em localidade mais povoada e dotada de maiores recursos, é classificada como central; escolas próximas, em número variável entre 5 e 20, tornam-se dela dependentes, para efeito de assistência técnica aos professores e uso comum de certo material. São estas últimas classificadas como satélites ou seccionais. (LOURENÇO FILHO, 1962, p. 58)

Lourenço Filho encerrou a análise das experiências do primeiro grupo de seu estudo, as que tivessem buscado a maior extensão dos serviços educativos ou a melhoria de sua qualidade, dando ênfase a estas duas experiências educacionais rurais. Destacou principalmente a solidez de projetos de escolas centrais a articular escolas de um só mestre e também os denominados núcleos escolares campesinos em países como Estados Unidos, México, Bolívia, Equador, Guatemala, Peru, Honduras, Nicarágua e Panamá.

Nas experiências educacionais rurais do segundo grupo analisadas pelo autor, nas tendentes a valorizar a escola num trabalho de extensão cultural, o Brasil era apresentado como exemplar em suas campanhas de alfabetização: 
Campanhas gerais de alfabetização, simultaneamente dirigidas a populações das cidades e do campo, têm sido realizadas em todos os países da América com mais elevadas taxas de analfabetismo. Nos meios rurais, geralmente se associam a programas de difusão de ideias sobre educação sanitária, educação social e econômica, e mesmo de tecnologia agrícola, com emprego de material audiovisual e distribuição gratuita de material de leitura. [...] Das campanhas desse tipo, com maior atuação sobre as áreas rurais, como se verifica pela documentação publicada, devem ser destacadas as do Brasil e do México. A primeira, iniciada em 1947, ainda prossegue. [...] No Brasil, a documentação estatística publicada em 1958 demonstra que, no período de 1947 a 1954, houve uma matrícula efetiva anual de 350 mil alunos, em média, com alfabetização média anual de 250 mil pessoas. [...] Estudos sobre o movimento da campanha brasileira, realizados em grandes cidades do sul, como São Paulo e Rio de Janeiro, demonstram que na matrícula aí obtida mais de 50\% dos alunos eram jovens e adultos recentemente emigrados de zonas rurais de outros Estados para essas cidades, em rápido desenvolvimento industrial. Sob esse aspecto, a campanha tem sentido nitidamente corretivo das deficiências do ensino rural em grande número dos Estados desse país, sobretudo de padrão de vida muito baixo nos do Nordeste. (LOURENÇO FILHO, 1962, p. 60-61)

Nas experiências do terceiro grupo, aquelas que visaram integrar os serviços de educação rural com outros serviços do Estado, os exemplos brasileiros destacados por Lourenço Filho foram os de formação de jovens líderes rurais e as experiências aqui executadas de desenvolvimento e reorganização das comunidades rurais. Nos dois casos, o autor ressaltou a importância da Campanha Nacional de Educação Rural, em curso no Brasil naquele momento:

Brasil - Neste país, a formação de jovens líderes rurais tem constituído um dos principais pontos do programa da chamada Campanha Nacional de Educação Rural, serviço experimental mantido pelo Ministério da Educação. O primeiro ensaio nesse sentido realizou-se em localidades do litoral do Estado de São Paulo, em cooperação com uma organização privada dedicada à difusão de práticas cooperativistas. Estendeu-se, em 1955, a outros pontos desse mesmo Estado, na forma de centros cooperativos de treinamento para jovens rurais, e mais tarde a outras regiões do país, de condições menos favoráveis, como alguns trechos do Estado de Goiás, de população rarefeita. Logo após, estabeleceu a Campanha acordo com o 
Estado do Rio Grande do Sul, de situação bem distinta pela densidade demográfica forte e regime de propriedade onde a experiência tem prosperado. Os modos de operação dos centros de treinamento são os seguintes: um grupo de jovens entre 13 e 17 anos é recrutado e submetido a um período de adaptação, em internato, pelo prazo de um mês. Formam-se equipes de 4 a 6 jovens, de acordo com as tendências e aptidões de cada qual; a essas equipes entrega-se a execução de projetos cooperativos de produção e consumo, com base em realizações concretas de produção agrícola e pecuária. Paralelamente, um programa de ensino geral e treinamento é desenvolvido, em 12 horas de aulas semanais, no mínimo. Os trabalhos diários no campo abrangem de 4 a 6 horas. As cooperativas organizam-se segundo a legislação do país, sob os auspícios de cada centro de treinamento, que inicialmente fornece o material necessário, em instrumentos agrícolas, sementes e adubos. A produção obtida é vendida, sendo o saldo dividido entre os executantes do projeto, na proporção das horas de trabalho efetivo de cada um. (LOURENÇO FILHO, 1962, p. 76-77)

A Campanha Nacional de Educação Rural, em 1963, estava em seu ano final de atividade, mas isto ainda era incerto, nebuloso. Desde o início da década de 1950, ao retornar de sua viagem de aprendizado sobre a educação rural mexicana, Lourenço Filho tivera papel crucial na criação e efetivação desta Campanha (SOUZA, 2013, p. 62). É possível que a ação de Lourenço Filho ao enviar à OEA seu estudo sobre educação rural fosse parte de uma articulação mais ampla a tentar influir nos rumos da educação rural brasileira neste ano decisivo de talvez extinção da Campanha. Para maior compreensão da Campanha Nacional de Educação Rural, entre outros textos, recomenda-se a leitura do trabalho pioneiro de Iraíde Marques de Freitas Barreiro (1997).

Na primeira parte de seu trabalho, Lourenço Filho apontara as principais características da educação rural, com dados comparativos de vários países das Américas. Na segunda parte, apresentou diversas experiências inovadoras da educação rural, dividindo-as em três grupos. Depois de abordar o que a educação rural era e o que poderia ser, na terceira e última parte de seu estudo, o autor encerrou seu texto analisando denominadores comuns de tais características e de tais experiências pioneiras. Entre outras classificações, destacou os fatores determinantes e os fatores colaterais a influenciar as 
atividades educativas no meio rural. Sobre os fatores determinantes, Lourenço Filho (1962, p. 93-94) afirmou que:

Os pequenos ensaios ou mais amplas realizações experimentais de educação rural têm surgido e tido mais desenvolvimento nos países em que, separada ou conjuntamente, estas circunstâncias ocorrem:

a) deficiência de oferta de ensino nas áreas rurais;

b) debilidade de demanda da educação escolar por parte das populações dessas áreas;

c) insuficiente articulação dos serviços escolares com outros serviços governamentais;

d) pequena ou nenhuma coordenação dos serviços educativos rurais com os planos e programas de desenvolvimento econômico e social, de caráter nacional ou regional.

Como fatores colaterais a influenciar as atividades educativas no meio rural, Lourenço Filho (1962, p. 96-97) destacou que:

Muitas experiências [educacionais no campo] têm estado ligadas a reformas de estrutura da vida rural, ou a certa ação preparatória a essas reformas. Dois outros fatores colaterais, mais de expressão negativa que positiva, têm existido. O primeiro decorre do fato de que qualquer movimento no sentido das reformas de estrutura levanta interesses muito poderosos. A linha de menor resistência para vencêlos ou, ao menos, esclarecê-los, tem sido a dos serviços educativos.

Nas observações finais de seu trabalho, Lourenço Filho (1962, p. 102103) foi mais claro quanto aos interesses muito poderosos que a educação rural deveria enfrentar:

Nos países da América Latina a distribuição da terra se mantém em condições arcaicas e antieconômicas, explicando os baixos índices de produtividade registrados. Dominam os latifúndios, pois menos de $2 \%$ de propriedades ocupam mais de metade da superfície total em numerosos países. [...] Dentro do latifúndio, como observam os analistas das relações entre estrutura agrária e educação, o trabalhador não tem possibilidade prática de fugir a seu estado de subordinação social e dependência econômica. Evidentemente, certo 
número de trabalhadores pode elevar-se até o nível de capatazes e auxiliares de alguma qualificação, mas o caminho para o progresso lhes é geralmente barrado. $O$ resultado é que a família rural não sente maior necessidade de mandar seus filhos à escola, parecendo-lhe desnecessário que aprendam senão as primeiras letras. Esse fato ajuda a explicar a enorme taxa de escolares que abandonam a escola rural, como também a falta de estímulo para estabelecer facilidades escolares adequadas. Aqueles que, por alguma razão, obtêm educação primária menos incompleta, logo que cheguem à adolescência se deslocam para as cidades. Os proprietários de terra não sentem assim necessidade de elevar os níveis educacionais nas áreas dominadas pelo latifúndio.

Para alicerçar esta abordagem entre educação rural e latifúndio, Lourenço Filho (1962, p. 103) em nota de rodapé citou como referência o estudo de Solon Barraclough (1962).

Esta foi a única parte do texto de Lourenço Filho a causar desconforto no Comitê de Ação Cultural da OEA. Nas atas de reunião de 13 de junho de 1963 deste Comitê, percebe-se certa contrariedade de parte dos membros quanto às relações entre latifúndio e insucesso da educação rural traçadas por Lourenço Filho. Nesta ocasião, o Presidente do Comitê, o brasileiro Clodomir Vianna Moog, teve que acalmar os ânimos. Porém, o resultado foi favorável a Lourenço Filho e seu texto original foi mantido no estudo encampado pela OEA:

Ao chegar à parte do estudo em que se indica que na maioria dos países da América Latina a distribuição da terra obedece a condições arcaicas e antieconômicas e predominam os latifúndios, o Presidente [do Comitê de Ação Cultural, o brasileiro Vianna Moog] suscitou uma troca de impressões a respeito. Apontou o Presidente que o problema do latifúndio, como questão socioeconômica que afeta diretamente à educação rural, igualmente que o da reforma agrária e o aproveitamento da terra, não devem ser encaradas unicamente desde o ponto de vista unilateral de que a solução dos mesmos consiste na mera supressão dos latifúndios, com a divisão de suas terras. A reforma agrária - indicou o Presidente - pode requerer diversas medidas: colonização de terras; expropriação, com redistribuição da terra; revisão das relações legais entre proprietários e trabalhadores rurais; extensão ao trabalhador rural dos benefícios da legislação social; fixação de impostos adequados. (OEA, 1963c, p. 106, nesta e nas próximas citações, a tradução do espanhol para o português é do 
autor do atual trabalho)

Lourenço Filho foi bem explícito nas conclusões de seu estudo sobre a educação rural. Era inviável debatê-la sem analisar as relações entre latifúndio, fracasso escolar e migração para as cidades.

O Comitê de Ação Cultural da OEA acrescentou ao texto de Lourenço Filho, como resumo deste estudo, 15 conclusões e 15 recomendações. Entre as conclusões, as mais relevantes foram:

5) Os cuidados dos governos no que se refere ao planejamento da educação rural obedecem à necessidade social inadiável de integrar grandes núcleos rurais à vida nacional.

6) A conquista de tal integração implica numa reforma agrária tecnicamente planejada, o que supõe, entre outras coisas, programas de desenvolvimento da comunidade rural (em função de um planejamento nacional tendendo a estabelecer o equilíbrio entre o desenvolvimento econômico e o desenvolvimento social), isenções tributárias, estabelecimento de preços mínimos remunerativos aos produtos rurais, assistência creditícia, facilidades para a industrialização dos produtos agrícolas pelos próprios camponeses, seguro agrícola etc.

7) Qualquer movimento com propensão a reformar as estruturas sociais frequentemente desperta a oposição de interesses conservadores muito poderosos.

8) Geralmente os serviços educativos têm sido úteis para lançar luz sobre esses interesses e no final vencê-los. (OEA, 1963d, p. 128)

Em suma, a educação rural era vista então como instrumento importante para a mudança das relações sociais no campo e um dos indutores da reforma agrária tecnicamente planejada.

Sintetizando as 15 conclusões e as 15 recomendações finais acrescentadas ao estudo de Lourenço Filho, a OEA divulgou em agosto de 1963 a Resolução V da Terceira Reunião do Conselho Interamericano Cultural da Organização dos Estados Americanos sobre a educação rural nas Américas, com 14 recomendações de ações aos seus Estados membros. Esta Resolução 
encontra-se anexa, ao término do atual trabalho.

\section{CONSIDERAÇÕES FINAIS}

Em dezembro de 1962, quando Lourenço Filho terminara a redação de seu estudo para a OEA, a Lei de Diretrizes e Bases da Educação Nacional - LDB - mal completara um ano de existência. Na LDB, determinava-se que todas as ações educativas no Brasil seriam incumbência do Ministério da Educação. Até então, grande parte dos projetos de educação rural brasileira estava sob responsabilidade do Ministério da Agricultura. Não se sabia muito bem como tal transferência se daria. Em 1963, a Campanha Nacional de Educação Rural estava em seu apogeu, mas, paradoxalmente, a ponto de ser encerrada. Ninguém sabia muito bem porque ou como ela seria extinta. A pressão campesina era forte para que as reformas de base do governo João Goulart fossem efetivamente implantadas no meio rural; entre elas, destacadamente, a reforma agrária. As nuvens tempestuosas de 1964 despontavam no horizonte. Era muita instabilidade conjunta.

Nesses momentos de grande incerteza, intelectuais do porte de Lourenço Filho tentavam agir como luminares em tempos sombrios. Ao enfatizar a importância da educação rural, Lourenço Filho buscou dar rumos à resolução de alguns dos problemas do meio rural brasileiro num período muito conflituoso. Em 1963, por mais prestígio que tivesse, uma coisa seria Lourenço Filho dizer 'eu recomendo que...'; outra coisa foi este intelectual ter construído os mecanismos para poder afirmar que 'a Organização dos Estados Americanos recomenda que.... É difícil conceber os usos que seriam dados por ele à Resolução da OEA sobre a educação rural. A tempestade autoritária desaguou em $1^{\circ}$ de abril de 1964 e os possíveis planos institucionais de Lourenço Filho para a educação rural brasileira naufragaram. 


\section{REFERÊNCIAS}

BARRACLOUGH. Solon. Estructura agraria y educación en América

Latina. Santiago de Chile: Organização das Nações Unidas para a Alimentação e Agricultura (FAO), 1962.

BARREIRO, Iraide Marques de Freitas. Cidadania e educação rural no Brasil:um estudo sobre a Campanha Nacional de Educação Rural. Tese de Doutorado. São Paulo: FE-USP, 1997.

CLAPCS - Centro Latino-Americano de Pesquisas em Ciências Sociais. Situação social da América Latina. Rio de Janeiro: CLAPCS, 1965.

HALL, Robert King. Observações sobre o ensino rural no Brasil. Revista Brasileira de Estudos Pedagógicos, v. 14, n. 38, p. 110-126, jan.-abril de 1950. É oportuno ressaltar que este número específico da revista foi dedicado quase que integralmente ao debate sobre a educação rural nas Américas.

INEP - Instituto Nacional de Estudos Pedagógicos. O INEP e os órgãos executores de planos especiais: realizações em 1956 e novos planos de trabalho. Revista Brasileira de Estudos Pedagógicos, v. 27, n. 65, p. 146-161, jan.março de 1957.

LOURENÇO FILHO, M. B. A educação rural no México. Relatório apresentado ao Exmo. Sr. Ministro da Educação e Saúde, Dr. Simões Filho. Rio de Janeiro: INEP, 1951.

LOURENÇO FILHO, M. B. A educação rural no México. Revista Brasileira de Estudos Pedagógicos, v. 17, n. 45, p. 108-198, jan.-março de 1952.

LOURENÇO FILHO, M. B.; CREEDY, L. A.; PIRE, E. A.; CASTILLO, I. La formation des maîtres ruraux. Paris: UNESCO, 1953.

LOURENÇO FILHO, M. B. Educação comparada. São Paulo: Melhoramentos, 1961.

LOURENÇO FILHO, M. B. Educação rural: documento preparado para a IV Reunião do Conselho Interamericano Cultural. Organização dos Estados Americanos. Rio de Janeiro: mimeo, 1962. O original encontra-se arquivado no CPDOC-FGV, no Rio de Janeiro, sob a indexação LF pi LOURENÇO FILHO 1962.12.00.

MONARCHA, C.; LOURENÇO FILHO, R. (Orgs.). Por Lourenço Filho: uma bibliografia. Brasília: INEP, 2001. 
OEA - Organização dos Estados Americanos. Boletin de actas: Comité de Accion Cultural. 337 ${ }^{\mathrm{a}}$ Reunión Ordinaria, de 15/01/1963a.

OEA - Organização dos Estados Americanos. Boletin de actas: Comité de

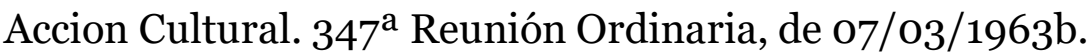

OEA - Organização dos Estados Americanos. Boletin de actas: Comité de Accion Cultural. 371 a Reunión Ordinaria, de 13/06/1963c.

OEA - Organização dos Estados Americanos. Estudio sobre educación rural: Resolución V de la Tercera Reunión del Consejo Interamericano Cultural. Washington, D. C.: OEA, 1963d.

SOUZA, R. F. de. A "Educação rural no México" como referência para o Brasil. Revista Educação em Questão, v. 45, n. 31, p. 61-81, jan.-abril de 2013.

WARDE, M. J. O itinerário de formação de Lourenço Filho por descomparação. Revista Brasileira de História da Educação, v. 3, n. 1 [5], p. 125-167, jan.junho de 2003.

MACIONIRO CELESTE FILHO é historiador graduado pela USP. Mestre e Doutor em Educação pela PUC-SP. Professor Assistente Doutor responsável pela área de História da Educação no Departamento de Educação da Faculdade de Ciências da UNESP, campus de Bauru/SP. Professor permanente no Programa de Pós-Graduação em Educação da Faculdade de Filosofia e Ciências da UNESP, campus de Marília/SP. Professor permanente do Programa de Pós-Graduação em Docência para a Educação Básica da Faculdade de Ciências da UNESP, campus de Bauru/SP.

E-mail: marciocelestefilho@gmail.com

(i) http://orcid.org/0000-0001-8798-9891

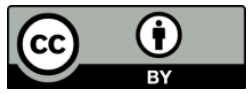

